\title{
Localization of the cellular retinoic acid binding protein (CRABP) gene relative to the acute promyelocytic leukemia-associated breakpoint on human chromosome 15
}

\author{
A. Geurts van Kessel ${ }^{1}$, H. de Leeuw ${ }^{1}$, E.J.Dekker ${ }^{2}$, L. Rijks ${ }^{3}$, N.Spurr ${ }^{4}$, D. Ledbetter ${ }^{5}$, \\ E.Kootwijk ${ }^{3}$, and M.J. Vaessen ${ }^{3}$ \\ ${ }^{1}$ Department of Human Genetics, University of Nijmegen, P.O. Box 9101, NL-6500 HB Nijmegen, The Netherlands \\ ${ }^{2}$ Hubrecht Laboratory, Netherlands Institute for Developmental Biology, Utrecht, The Netherlands \\ ${ }^{3}$ Department of Cell Biology and Genetics, Erasmus University, Rotterdam, The Netherlands \\ ${ }^{4}$ Human Genetic Resources Laboratory, ICRF, Potters Bar, UK \\ ${ }^{5}$ Institute for Molecular Genetics, Baylor College of Medicine, Houston, Texas, USA
}

Received October 1, 1990 / Revised December 10, 1990

\begin{abstract}
Summary. A human genomic fragment comprising the cellular retinoic acid binding protein (CRABP) gene was isolated. By using a panel of somatic cell hybrids, this gene could be assigned to human chromosome 15 . Subsequently, a possible involvement of the CRABP gene in translocation $(15 ; 17)(\mathrm{q} 22 ; \mathrm{q} 11)$ positive acute promyelocytic leukemia (APL) was investigated. Although transposition of the CRABP gene could be demonstrated, we did not observe any gross CRABP rearrangement in a series of primary APL patients, nor in the acute myeloblastic leukemia cell line HL-60. Thus, the observed lack of CRABP expression in these leukemic cells may not be caused by disruption of its gene. CRABP maps to the region $15 \mathrm{q} 22$-qter.
\end{abstract}

\section{Introduction}

Retinoic acid (RA), a biologically active metabolite of retinol (vitamin A), plays an important role in various growth and differentiation processes during both embryonic development and adult life (Lotan 1980; Omori and Chytil 1982; Chytil 1984; Oikarinen et al. 1985). RA has also been reported to induce in vitro differentiation of cancerous cells, including human and murine embryonal carcinoma cells (Strickland and Mahdavi 1978; Andrews et al. 1986), the acute myeloblastic leukemia cell line HL-60, the monoblastic leukemia cell line U-937 (Breitman et al. 1980; Hozumi 1982; Dalton et al. 1988) and blasts from acute myeloid leukemia (AML) patients in primary culture (Breitman et al. 1981; Honma et al. 1983). Consequently, RA has on various occasions been

Offprint requests to: A. Geurts van Kessel suggested as a potent agent for the treatment of AML, in particular acute promyelocytic leukemia (APL) patients (Breitman et al. 1981; Meng-er et al. 1988; Hassan and Rees 1990).

The molecular mechanisms underlying RA action are currently the subject of intensive investigations. Recent work indicates that RA acts as an endogenous signal that regulates gene expression via nuclear receptors (RARs) in a dose-dependent way (Edwards and McBurney 1983; Evans 1988). The discovery of an RA gradient in the developing embryo by Thaller and Eichele (1987) is in full agreement with this notion. In addition to these nuclear receptors, cellular (cytoplasmic) RA-binding protein (CRABP) seems to play a role in RA-mediated signal transduction. During embryonic development, the spatial and temporal expression of the CRABP gene appears to be strictly regulated (Vaessen et al. 1989, 1990; Perez-Castro et al. 1989; Maden et al. 1988, 1989a). Hence, it has been suggested that CRABP could be involved in the formation of gradients of RA across various developing tissues (Maden et al. 1989b).

Here, we report the isolation of the human homolog of the CRABP gene and its chromosomal localization. Subsequently, a possible involvement of CRABP in the APL specific translocation $(15 ; 17)(\mathrm{q} 22 ; \mathrm{q} 11)$ (Larson et al. 1984) was evaluated. Interestingly, although both primary APL cells and the acute myeloblastic leukemiaderived cell line HL-60 are responsive to differentiationinduction by RA, they seem to be deficient in the cellular RA-binding protein (Douer and Koeffler 1982; Jetten et al. 1987; Allegretto et al. 1983; Largman et al. 1989; C. Chomienne, personal communication). By using our newly isolated CRABP probe, we have studied its expression at the RNA level in HL-60 cells prior to and after differentiation-induction. 


\section{Materials and methods}

\section{Cells and culture conditions}

The panel of human-rodent hybrid cell lines used for the chromosomal localization of the CRABP gene has been described before (Geurts van Kessel et al. 1983), as have the t(15;17)-derived cell hybrids C73/PJT2A1 and P12.3B6 (Sheer et al. 1983; van Tuinen et al.1987). The hybrid (and parental) cells were grown in F10 or DMEM medium according to standard procedures. Chromosome analyses, using GTG-banding or R-banding after heat denaturation, and DNA extractions were carried out on the same batches of cells.

HL-60 cells were cultured in RPMI-1640 medium supplemented with $10 \%$ fetal calf serum, glutamine $(2 \mathrm{~m} M)$, penicillin $(100 \mathrm{U} / \mathrm{ml})$ and streptomycin $(100 \mu \mathrm{g} / \mathrm{ml})$. After addition of $10^{-6} M$ all-trans RA (from a $3 \mathrm{mg} / \mathrm{ml}$ stock in dimethyl sulfoxide; DMSO) or $1 \% \mathrm{DMSO}$, the cells were allowed to differentiate for 6 days (Breitman et al. 1980). During this period, the medium was replenished twice. As estimated from May Grünwald-Giemsa stained cytospin preparations, over $70 \%$ of the cells had differentiated into granulocytes and monocytes, respectively.

\section{Origin of the human CRABP probe}

Screening of a human genomic phage library (CMLO, kindly provided by Dr. G. Grosveld) with mouse and chicken CRABP cDNA probes (Vaessen et al. 1989, 1990) yielded several CRABP-positive clones. A 700-bp repeat-free human XhoII fragment was subcloned into the $B a m \mathrm{HI}$ site of pTZ18R and its nucleotide sequence was determined via the dideoxy chain termination method (Sanger et al. 1977).

\section{Southern analysis}

DNAs were extracted according to standard procedures (Jeffreys and Flavell 1977). Following cleavage with restriction enzymes, DNA fragments were separated by electrophoresis on agarose gels and transferred to Genescreen (NEN) filters (Southern 1975). The human CRABP probe used was labeled with ${ }^{32} \mathrm{P}$ using random priming as described by Feinberg and Vogelstein (1983). Hybridizations were carried out overnight at $65^{\circ} \mathrm{C}$ in the presence of $0.5 M$ phosphate, $7 \%$ SDS and $1 \mathrm{~m} M$ EDTA. Filters were washed at $65^{\circ} \mathrm{C}, 3 \times 5 \mathrm{~min}$, in $40 \mathrm{mM}$ phosphate $/ 0.1 \%$ SDS, followed by a 30 -min wash in $10 \mathrm{~m} M$ phosphate $0.1 \%$ SDS. X-ray films were exposed using intensifier screens.

\section{Northern analysis}

Total RNA was isolated from cell lines using the $\mathrm{LiCl} /$ urea method described by Auffray and Rougeon (1980), electrophoresed on 1\% agarose gels in the presence of formaldehyde, and transferred to Genescreen filters (Maniatis et al. 1982). Prior to electrophoresis, ethidium bromide was added to the RNA samples in order to allow visualization of the ribosomal RNAs in the gel (Fourney et al. 1989). Probe labeling, hybridization (in the presence of $10 \%$ dextran sulfate) and washing conditions were essentially as described above.

\section{Results and discussion}

A 700-bp repeat-free human XhoII CRABP fragment was subcloned into the Bam-Hl site of pTZ18R and its nucleotide sequence was determined (details will be published elsewhere). Comparison of this sequence with the murine cDNA sequence revealed a $92 \%$ homology in the coding region from nucleotide 380 to 464 (num-

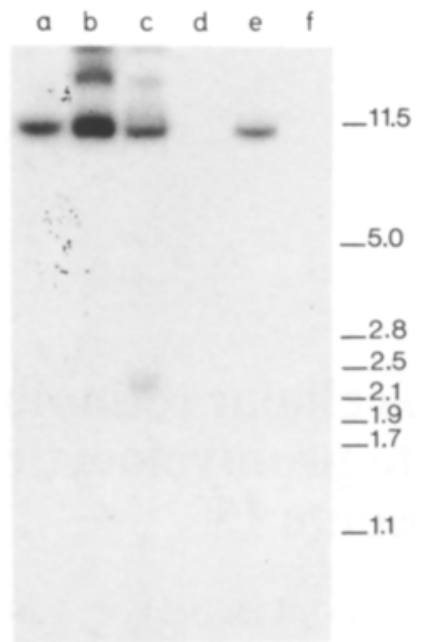

Fig. 1. Southern blot analysis of EcoR1-digested normal human fibroblast $(a)$, myeloblastic leukemia cell line HL-60 (b), chromosome-15-only somatic cell hybrid HORL-1 (c), 15/17 translocationderivative positive hybrid C73/PJT2A1 (d), 17/15 translocationderivative positive hybrid $\mathrm{P} 12.3 \mathrm{~B} 6(e)$ and control mouse $(f)$ DNAs, after hybridization with the human CRABP probe. The slow migrating $(>10 \mathrm{~kb})$ bands $(b, c)$ are a result of incomplete digestions (not observed in other similarly obtained preparations). The indicated molecular weight markers are derived from co-electrophoresed PstI-digested bacteriophage lambda DNA (in kb)

bering according to Vaessen et al. 1989). Nucleotide 464 represents an exon/intron boundary, which is apparently conserved in the human and bovine genome (Shubeita et al. 1987). Comparison of the predicted amino acid sequence revealed that our human clone codes for a protein identical to CRABP from other species (bovine: Shubeita et al.1987; mouse: Vaessen et al. 1989). Hence, the 700-bp subclone was named HuCRABP and used as a human CRABP-specific probe in the present study.

For the chromosomal localization of the human CRABP gene, a panel of 19 well-defined (Geurts van Kessel et al. 1983) human-rodent somatic cell hybrids was used. High molecular weight DNA extracted from these cells and control rodent (hamster, mouse) and human cells was cleaved with EcoR1 and, after Southern blotting, analyzed for the presence of CRABP sequences using HuCRABP DNA as a probe. This probe hybridizes to a human $E c o$ R 1 fragment of approximately $10 \mathrm{~kb}$ (see Fig. 1) and does not hybridize to mouse or hamster DNA under the stringency conditions used. A high concordancy score (95\%) was observed for chromosome 15 (Table 1), whereas for all other human chromosomes, concordancy scores were invariably lower. Therefore, we conclude that the CRABP gene must reside on human chromosome 15 . The only discordant clone (see Table 1) had retained chromosome 15 in a low percentage of cells $(10 \%)$. This assignment is not in agreement with a previous report in which a bovine cDNA was used as a probe under low stringency conditions (Nilsson et al. 1988). The most likely explanation for this descrepancy is that the previously observed hybridization signals were the result of cross-hybridization of the bovine probe with a related gene(s) on human chromosome 3 . 
Table 1. Correlation between the presence or absence of human chromosomes and the CRABP gene in 19 human-rodent somatic cell hybrids

\begin{tabular}{|c|c|c|c|c|c|}
\hline \multirow[t]{2}{*}{ Chromosome } & \multicolumn{4}{|c|}{ Chromosome/CRABP; no. of clones } & \multirow{2}{*}{$\begin{array}{l}\text { Discordancy } \\
(\%)\end{array}$} \\
\hline & $+1+$ & $+1-$ & $-1+$ & $-1-$ & \\
\hline 1 & 4 & 5 & 6 & 4 & 58 \\
\hline 2 & 2 & 2 & 8 & 7 & 53 \\
\hline 3 & 5 & 4 & 5 & 5 & 47 \\
\hline 4 & 6 & 3 & 4 & 6 & 37 \\
\hline 5 & 5 & 5 & 5 & 4 & 43 \\
\hline 6 & 5 & 4 & 5 & 5 & 47 \\
\hline 7 & 5 & 2 & 5 & 7 & 37 \\
\hline 8 & 7 & 6 & 3 & 3 & 47 \\
\hline 9 & 6 & 6 & 4 & 3 & 53 \\
\hline 10 & 3 & 4 & 7 & 5 & 58 \\
\hline 11 & 4 & 5 & 6 & 4 & 58 \\
\hline 12 & 7 & 2 & 3 & 7 & 26 \\
\hline 13 & 7 & 5 & 3 & 4 & 42 \\
\hline 14 & 8 & 5 & 2 & 4 & 37 \\
\hline 15 & 10 & $1^{\mathrm{a}}$ & 0 & 8 & 5 \\
\hline 16 & 7 & 6 & 3 & 3 & 47 \\
\hline 17 & 9 & 5 & 1 & 4 & 32 \\
\hline 18 & 4 & 5 & 6 & 4 & 58 \\
\hline 19 & 7 & 5 & 3 & 4 & 42 \\
\hline 20 & 9 & 7 & 1 & 2 & 42 \\
\hline 21 & 7 & 7 & 3 & 2 & 53 \\
\hline 22 & 7 & 6 & 3 & 3 & 47 \\
\hline $\mathrm{X}$ & 6 & 2 & 4 & 7 & 32 \\
\hline
\end{tabular}

a This hybrid clone contains chromosome 15 in a low percentage of cells $(10 \%)$

In order to establish the localization of the CRABP gene relative to the acute promyeolocytic leukemia (APL)-associated $\mathrm{t}(15 ; 17)(\mathrm{q} 22 ; \mathrm{q} 11)$ breakpoint on chromosome 15, hybrid cell lines derived from the fusion of cells from two $\mathrm{t}(15 ; 17)$-positive APL patients, having retained either the $15 / 17$ or the $17 / 15$ translocation derivative in the absence of a normal chromosome 15, were subjected to Southern blot analysis. A humanchromosome-15-only hybrid (HORL-1, N. Spurr unpublished result), normal human fibroblasts and the acute myeloblastic leukemia cell line HL-60 were also included in this analysis. Figure 1 shows that HORL-1 (lane c) is positive for CRABP; this confirms our localization of this gene on human chromosome 15 . Similarly hybridizing $E c o \mathrm{R} 1$ fragments were found in normal human fibroblast (lane a) and HL-60 (lane b) DNAs, indicating that no gross rearrangements have occurred in this CRABP sequence in the leukemic cell line HL-60. Hybrid C73/ PJT2A1 (lane d), which contains the $15 / 17$ derivative of the $t(15 ; 17)$, is negative, whereas P12.3B6 (lane e) containing the $17 / 15$ derivative of this translocation is positive for CRABP. From these results, we conclude that, as a result of the $t(15 ; 17)$, CRABP is transposed from chromosome 15 to chromosome 17 in APL. As in HL-60 DNA, the APL-derived hybrids show no aberrantly hybridizing fragments. Similar results were obtained with
BamHI-cleaved (hybrid) DNAs. In addition, DNAs from another eight $t(15 ; 17)$-positive APL patients were tested for the presence of gross rearrangements in the CRABP gene via EcoR1 or BamH1 digestion and Southern blotting. Again, no aberrantly hybridizing fragments were observed (not shown). Apparently, the break in $t(15 ; 17)$ positive APL does not occur within restriction fragments hybridizing to our CRABP probe.

Previously, it was reported that, at the protein level, no CRABP expression could be detected in the myeloblastic leukemia-derived cell line HL-60 (Douer and Koeffler 1982; Jetten et al. 1987; Largman et al. 1989). In order to extend these studies to the RNA level, a Northern blot analysis was carried out using RNA extracted from exponentially growing HL-60 cells and HL-60 cells that were induced to differentiate for 6 days using $10^{-6} M$ all-trans RA (granulocytic differentiation) or $1 \%$ DMSO (monocytic differentiation) according to standard protocols (Breitman et al. 1980). By using HuCRABP as a probe, no CRABP transcripts could be detected in any of the HL-60 derived RNAs (not shown). DMSO induction of CRABP was previously observed in a murine embryonal carcinoma (EC) cell system (Vaessen et al. 1989). In HL-60 cells, however, DMSO exposure does not result in expression of detectable amounts of CRABP mRNA. A positive CRABP signal was observed in a co-electrophoresed RNA sample extracted from the human EC cell line N-Tera 2 (Andrews et al. 1986). Since the CRABP gene does not seem to be grossly disrupted in HL-60 cells (or primary APL samples), lack of CRABP expression in these cells may be caused by transcriptional repression.

In conclusion, we have isolated genomic fragments corresponding to the human CRABP gene. Subsequently, this gene could be localized on human chromosome 15, distal to the APL-associated breakpoint (region 15q22-ter). As a result of this translocation, the CRABP gene does not seem to be grossly rearranged. Further experiments are required to evaluate a possible role of CRABP in (aberrant) myeloid differentiation processes and the development of APL.

Acknowledgements. The authors thank Drs. D. Bootsma and H. H. Ropers for advice and support, Drs. D. Sheer and E. Solomon for providing hybrid cell DNAs, and Dr.R.Berger for providing DNAs from primary APL patients. We also acknowledge Dr. G. Grosveld for the gift of the CMLO library and Mrs. M. Ariaans for expert secretarial assistance. This work was supported by the Dutch Cancer Society (Koningin Wilhelmina Fonds) and the Dutch Organization for Scientific Research (NWO-BION).

\section{References}

Allegretto EA, Kelly MA, Donaldson CA, Levine N, Pike JW, Haussler MR (1983) High pressure liquid chromatographic detection of intracellular retinoid binding proteins from cultured cell and tumor cytosols. Biochem Biopyhs Res Commun 116: $75-81$

Andrews PW, Gonczol E, Plotkin SA, Dignazio M, Oosterhuis JW (1986) Differentiation of tera-2 human embryonal carcinoma cells into neurons and HCMV permissive cells. Differentiation $31: 119-126$ 
Auffray C, Rougeon F (1980) Purification of mouse immunoglobulin heavy chain messenger RNA's from total myeloma tumor RNA. Eur J Biochem 107:303-314

Breitman TR, Selonick SE, Collins SJ (1980) Induction of differentiation of the human promyelocytic leukemia cell line (HL-60). Proc Natl Acad Sci USA 77:2936-2940

Breitman TR, Collins SJ, Keene BR (1981) Terminal differentiation of human promyelocytic leukaemia cells in primary culture in response to retinoic acid. Blood 57:1000-1004

Chytil F (1984) Retinoic acid: biochemistry, pharmacology, toxicology and therapeutic use. Pharmacol Rev 36:935-975

Dalton WT, Ahearn MJ, McCredie KB, Freireich EJ, Stass SA, Trujillo (1988) HL-60 cell line was derived from a patient with FAB-M2 and not FAB-M3. Blood $71: 242-247$

Douer D, Koeffler HP (1982) Retinoic acid: inhibition of the clonal growth of human myeloid leukemia cells. J Clin Invest $69: 277-282$

Edwards MKS, McBurney MW (1983) The concentration of retinoic acid determines the differentiated cell types formed by a teratocarcinoma cell line. Dev Biol 98:187-191

Evans RM (1988) The steroid and thyroid hormone receptor super family. Science 240:889-895

Feinberg AP, Vogelstein B (1983) A technique for radiolabeling DNA restriction endonuclease fragments to high specific activity. Anal Biochem 132:6-13

Fourney RM, Miyakoshi J, Day RS III, Paterson MC (1989) Northern blotting: efficient RNA staining and transfer. Focus 10:5-7

Geurts van Kessel A, Tetteroo P, Von dem Borne A, Hagemeijer A, Bootsma D (1983) Expression of human myoloid associated surface antigens in human-mouse myeloid cell hybrids. Proc Natl Acad Sci USA 80:3748-3752

Hassan T, Rees J (1990) Triple combination of retinoic acid + 6thioguanine + hexamethylene bisacetamide induces differentiation of human AML blasts in primary culture. Leuk Res 14: 109-117

Honma Y, Fujita Y, Hozumi M, Sampik, Sakuri M, Tsushima S, Hiroski N (1983) Induction of differentiation of human acute nonlymphocytic leukaemic cells in primary culture by inducers of differentiation of human myeloid leukaemic cell line HL-60. Eur J Cancer Clin Oncol 19:251-261

Hozumi M (1982) Differentiation inducers of human myeloid leukaemia cells and anticancer agents. Nippon Rinsho 40:1865

Jeffreys AJ, Flavell RA (1977) A physical map of the DNA regions flanking the rabbit $\beta$ globin gene. Cell 12:429-439

Jetten AM, Anderson K, Deas MA, Kajechika DH, Lotan R, Rearick JI, Shudo K (1987) New benzoic acid derivatives with retinoid activity; lack of direct correlation between biological activity and binding to cellular retinoic acid binding protein. Cancer Res 47:3523-3527

Largman C, Detmer K, Corral JC, Hack FM, Lawrence J (1989) Expression of retinoic acid receptor alpha mRNA in human leukemia cells. Blood 74:99-102

Larson RA, Kondo K, Vardiman JW, Butler AE, Golomb HM, Rowley JD (1984) Every patient with acute promyelocytic leukemia may have a 15;17 translocation. Am J Med 76:827-841

Lotan R (1980) Effects of vitamin A and its analogs (retinoids) on normal and neoplastic cells. Biochim Biophys Acta 605:33-91

Maden M, Ong DE, Summerbell D, Chytil F (1988) Spatial distribution of cellular protein binding to retinoic acid in the chick limb bud. Nature 335:733-735

Maden M, Ong DE, Summerbell D, Chytil F (1989a) The role of retinoid-binding proteins in the generation of patterns in the developing limb, the rengenerating limb, and the nervous system. Development [Suppl]:109-119

Maden M, Ong DE, Summerbell D, Chytil F, Hirst EA (1989b) Cellular retinoic acid-binding protein and the role of the retinoic acid in the development of the chick embryo. Dev Biol 135: $124-132$

Maniatis T, Fritsch EF, Sambrook J (eds) (1982) Molecular cloning: a laboratory manual. Cold Spring Harbor Laboratory, Cold Spring Harbor, NY

Meng-er H, Yu-Chen Y, Shu-rong C, Jin-ren C, Jia-Xiang L, Lin Z, Long-jun G, Zhen-yi W (1988) Use of all trans retinoic acid in the treatment of acute promyelocytic leukaemia. Blood 72 : $567-572$

Nilsson MHL, Spurr NK, Saksena P, Busch C, Nordlinder H, Peterson PA, Rask L, Sundelin J (1988) Isolation and characterization of a cDNA clone corresponding to bovine cellular retinoic-acid-binding protein and chromosomal localization of the corresponding human gene. Eur J Biochem 173:45-51

Oikarinen AI, Oikarinen H, Uitto J (1985) Demonstration of cellular retinoic acid binding protein in cultured human skin fibroblasts. Br J Dermatol 113:529-535

Omori M, Chytil F (1982) Mechanism of vitamin-A action; gene expression in retinol-deficient rats. J Biol Chem 257:1437014374

Perez-Castro-AV, Toth-Rogler LE, Wei LN, Nguyen-Huu MC (1989) Spatial and temporal pattern of expression of the cellular retinoic acid binding protein and the cellular retinol-binding protein during mouse embryogenesis. Proc Natl Acad Sci USA $96: 8813-8817$

Sanger F, Nicklen S, Coulson AR (1977) DNA sequencing using chain-terminating inhibitors. Proc Natl Acad Sci USA 74: 5463-5467

Sheer D, Hiorns LR, Stanley KF, Goodfellow PN, Swallow DM, Povey S, Heisterkamp N, Groffen J, Stephenson JR, Solomon E (1983) Genetic analysis of the $15 ; 17$ chromosome translocation associated with acute promyelocytic leukemia. Proc Natl Acad Sci USA 80:5007-5011

Shubeita HE, Sambrook JF, McCormick AM (1987) Molecular cloning and analysis of functional cDNA and genomic clones encoding bovine cellular retinoic acid binding protein. Proc Natl Acad Sci USA 84:5645-5649

Southern EM (1975) Detection of specific sequences among DNA fragments separated by gel electrophoresis. J Mol Biol 98: 503517

Strickland S, Mahdavi V (1978) The induction of differentiation in teratocarcinoma stem cells by retinoic acid. Cell $15: 393-403$

Thaller C, Eichele G (1987) Identification and spatial distribution of retinoids in the developing chick limb bud. Nature 327:625628

Tuinen P van, Rich DC, Summers KM, Ledbetter DH (1987) Regional mapping panel for human chromosome 17: application to neurofibromatosis type 1 . Genomics $1: 374-381$

Vaessen MJ, Kootwijk E, Mummery C, Hilkens J, Bootsma D, Geurts van Kessel A (1989) Preferential expression of cellular retinoic acid binding protein in a subpopulation of neural cells in the developing mouse embryo. Differentiation 40:99-105

Vaessen MJ, Meijers JHC, Bootsma D, Geurts van Kessel A (1990) The cellular retinoic acid binding protein is expressed in tissues associated with retinoic acid induced malformations. Development 110:371-378
Note added in proof. After submission of this manuscript, three independent groups reported that the APL breakpoint at chromosome 17 is located within the retinoic acid receptor- $\alpha$ gene. 